\title{
Faster onset of bronchodilation with formoterol than with salmeterol in patients with stable, moderate to severe COPD: Results of a randomized, double-blind clinical study
}

\author{
John Kottakis $M D^{1}$, Giovanni Della Cioppa $\mathrm{MD}^{1}$, Jacques Creemers $\mathrm{MD}^{2}$, \\ Louis Greefhorst $\mathrm{PhD}^{3}$, Violette Leclerc $\mathrm{MD}^{4}$, Riccardo Pistelli $\mathrm{MD}^{5}$, \\ Tim Overend $\mathrm{PhD}^{1}$, Denise Till MSc${ }^{1}$, Günter Rapatz $\mathrm{MSc}^{1}$, Vincent Le Gros MD ${ }^{6}$, \\ Demosthenes Bouros $\mathrm{MD}^{7}$, Nikolaos Siafakas $\mathrm{MD}^{7}$
}

\begin{abstract}
J Kottakis, G Della Cioppa, J Creemers, et al. Faster onset of bronchodilation with formoterol than with salmeterol in patients with stable, moderate to severe COPD: Results of a randomized, double-blind clinical study. Can Respir J 2002;9(2):107-115.
\end{abstract}

OBJECTIVES: To compare the onset and magnitude of bronchodilation after dry powder inhalations of formoterol fumarate (Foradil Aerolizer) versus salmeterol xinofoate (Serevent Diskus) with respect to normalized $(*)$ forced expiratory volume in $1 \mathrm{~s}$ area under the curve 0 to $1 \mathrm{~h}$ after inhalation $\left(\mathrm{FEV}_{1} \mathrm{AUC}^{*}{ }_{0-1 \mathrm{~h}}\right)$. DESIGN: A double-blind, double-dummy, multicentre, randomized, placebo controlled, single-dose, five-period crossover study. SETTING: Five centres in four countries - one centre each in France, Greece and Italy, and two centres in the Netherlands. PATIENTS: Forty-seven patients aged 42 to 80 years (mean age 63.5 years) with chronic obstructive pulmonary disease (COPD) stage II and III, and mean baseline FEV 1.17 L (range 0.56 to $1.77 \mathrm{~L}$ ).
INTERVENTIONS: Patients inhaled single doses of formoterol dry powder (12 and $24 \mu \mathrm{g})$, single doses of salmeterol (50 and $100 \mu \mathrm{g}$ ) and matching placebo on five separate days. MAIN RESULTS: The estimates of treatment difference in absolute terms $(0.086 \mathrm{~L})$ and percentage change from predose baseline $(7.8 \%)$ for the primary end point, FEV $_{1}$ AUC* $_{0-1 \mathrm{~h}}$, showed that formoterol $12 \mu \mathrm{g}$ was statistically significantly superior to salmeterol $50 \mu \mathrm{g}(\mathrm{P}=0.0044$ and $\mathrm{P}=0.0021$, respectively $)$. In addition, both doses of formoterol were statistically superior to placebo for both absolute improvement and percentage change $(\mathrm{P}=0.0001)$. The analysis of secondary variables also confirmed the superiority of formoterol over salmeterol.

CONCLUSIONS: Formoterol is associated with a faster onset of bronchodilation than salmeterol in patients with COPD.

Key Words: Beta $a_{2}$-agonists; Bronchodilators; Chronic obstructive pulmonary disease; Clinical trial; COPD; Formoterol; Salmeterol

Résumé à la page suivante

${ }^{1}$ Novartis Pharma, Horsham, United Kingdom; ${ }^{2}$ Catharina Ziekenhuis, Eindhoven, Netherlands; ${ }^{3}$ Streetziekenhuis Midden-Twente, Hengelo, Netherlands; ${ }^{4}$ Société Aster Cephac, Paris, France; ${ }^{5}$ Complesso Integrato Columbus, Roma, Italy; ${ }^{6}$ Novartis Pharma, Paris, France;

${ }^{7}$ University Hospital, Crete, Greece

Correspondence and reprints: Dr John Kottakis, Novartis Horsham Research Centre, Wimblehurst Road, Horsham, West Sussex RH12 5AB, United Kingdom. Telephone +44-1403-323586, fax +44-1403-323060, e-mail ioannis.kottakis@pharma.novartis.com 


\section{Amorce plus rapide de la bronchodilatation avec le formotérol qu'avec le salmétérol chez des patients atteints d'une BPCO modérée ou grave : résultats d'un essai clinique à double insu avec répartition aléatoire}

OBJECTIF : Comparer l'amorce et l'importance de la bronchodilatation provoquée par l'inhalation de fumarate de formotérol en poudre sèche (Foradil Aerolizer) au xinafoate de salmétérol (Serevent Diskus) en tenant compte de l'aire sous la courbe (ASC) normalisée* du VEMS (volume expiratoire maximal par seconde) de 0 à $1 \mathrm{~h}$ après l'inhalation (VEMS ASC**-1 h).

PLAN D'ÉTUDE : Essai multicentrique, à double insu et à double placebo, avec répartition aléatoire, croisé avec cinq périodes et à dose unique. LIEU : Cinq centres dans quatre pays : un en France, en Grèce et en Italie respectivement et deux aux Pays-Bas.

PATIENTS : Quarante-sept patients âgés de 42 à 80 ans (âge moyen :
63,5 ans), atteints d'une BPCO (bronchopneumopathie chronique obstructive) de stade II ou III et ayant un VEMS moyen au départ de 1,17 1 (intervalle de 0,56 à 1,77 1) ont participé à l'étude.

INTERVENTIONS : Les patients ont inhalé une dose unique de formotérol en poudre sèche (12 et $24 \mu \mathrm{g}$ ), une dose unique de salmétérol (50 et $100 \mu \mathrm{g})$ et un placebo correspondant au cours de cinq jours différents.

PRINCIPAUX RÉSULTATS : Les estimations de différences entre traitements, en valeurs absolues $(0,0861)$ et en pourcentage $(7,8 \%)$ par rapport aux valeurs de départ avant l'administration des doses, montrent, en ce qui concerne le principal critère d'évaluation (VEMS ASC ${ }_{0-1} h_{\text {h }}$ ), que le formotérol $12 \mu \mathrm{g}$ s'est avéré statistiquement supérieur au salmétérol $(50 \mu \mathrm{g})(\mathrm{P}=0,0044$ et $\mathrm{P}=0,0021$ respectivement $)$. De plus, les deux doses de formotérol se sont également révélées supérieures au placebo, et ce, tant pour l'amélioration absolue que pour les variations de pourcentage $(\mathrm{P}=0,0001)$. L'analyse des variables secondaires a aussi confirmé la supériorité du formotérol sur le salmétérol.

CONCLUSION : Le formotérol est associé à une amorce plus rapide de la bronchodilatation que le salmétérol chez des patients atteints d'une BPCO.
$I^{n}$ In patients with asthma, formoterol has a rapid onset of action that is similar to salbutamol (albuterol). Single-dose studies in adults with asthma have shown that inhalation of 12 or $24 \mu \mathrm{g}$ of formoterol (as an aerosol or dry powder) provides prompt bronchodilation, with onset of action observed within 1 to 3 min of administration (1-5). In contrast, salme-

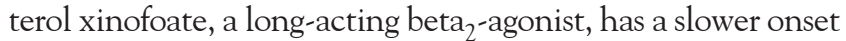
of bronchodilating action -7 to $17 \mathrm{~min}$ after inhalation $(6,7)$.

Chronic obstructive pulmonary disease (COPD) is characterized by airflow obstruction caused by chronic bronchitis and emphysema. Unlike patients with asthma, patients with COPD present with poorly reversible bronchoconstriction, which is the result of irreversible changes in the lung parenchyma and airways due, in most cases, to cumulative exposure to tobacco smoke. Pharmacotherapy in COPD is given to improve symptoms and reduce complications, and bronchodilators are central to the management of symptoms, used on an as-needed basis or regularly (8). In patients with COPD, regular beta ${ }_{2}$-agonist treatment is intended to provide relief from existing symptoms, unlike asthma, in which regular beta ${ }_{2}$-agonist treatment is focused on protecting the airways from challenge and preventing symptoms.

Both formoterol and salmeterol have been shown to be effective in the treatment of COPD (9-14), demonstrating improvements in symptoms (particularly dyspnea) and quality of life. However, because these two long-acting beta $_{2}$-sympathomimetic drugs differ from one another with respect to a number of pharmacological properties (15), the speed of onset of bronchodilation and symptom relief is likely to be of great importance to the patient with COPD. In this context, the present study was conducted to investigate the speed of onset of effect of formoterol delivered by a dry powder inhaler (Foradil Aerolizer, Norvartis Pharma AG, Switzerland) compared with inhaled salmeterol xinofoate dry powder (Serevent Diskus, GlaxoSmithKline, United Kingdom) in patients with stable, moderate to severe COPD (stages II and III).

\section{Study design}

\section{PATIENTS AND METHODS}

This was a multicentre, randomized, double-blind, doubledummy, placebo controlled, single-dose, five-period crossover study in male and female patients with stage II and III COPD diagnosed according to American Thoracic Society criteria, ie, forced expiratory volume in $1 \mathrm{~s}\left(\mathrm{FEV}_{1}\right)$ less than $50 \%$ of the predicted value (8). This design minimized bias and allowed for a within-patient, placebo controlled comparison. To blind the trial, a double-dummy technique was employed, using the study treatments as follows: formoterol dry powder capsules, each containing $12 \mu \mathrm{g}$ formoterol fumarate (Foradil) delivered via the Aerolizer device; salmeterol $50 \mu \mathrm{g}$ metered dose delivered via dry powder inhaler (Serevent Diskus); placebo dry powder (lactose) capsules matched to formoterol dry powder capsules delivered via the Aerolizer device; and placebo Serevent Diskus (empty). To ensure that lack of taste with (single-dose) placebo Diskus inhalation did not lead to unblinding, formoterol (either active or placebo) was always administered first. This was considered to blunt the perception of any lack of taste on the part of the patient and thus ensure treatment blinding.

At visit 1 (screening), spirometry was performed to help to determine disease severity. In addition, a reversibility test with dry powder salbutamol $400 \mu \mathrm{g}$ (Ventodisk; GlaxoSmithKline, United Kingdom; $200 \mu \mathrm{g}$ per inhalation) was carried out. Eligible patients had to demonstrate an increase in $\mathrm{FEV}_{1}$ (30 min after inhalation of salbutamol) of $5 \%$ or greater from the baseline value, but not greater than $12 \%$ of the patient's predicted normal value, allowing for most measurements to fall within the normal variability of the $\mathrm{FEV}_{1}$ measurement $(16,17)$.

At visit 2, patients were randomly assigned to one of the sequences of treatments from a $5 \times 5$ Latin square design comparing single doses of formoterol dry powder (12 and $24 \mu \mathrm{g})$ with single doses of salmeterol dry powder (50 and $100 \mu \mathrm{g})$ 
and placebo. All treatments were administered in a doubleblind manner, so that at each dosing interval, every patient received four separate inhalations - two dry powder capsules (formoterol or matching placebo), each inhaled from a separate Aerolizer device, plus one inhalation from each of two separate Diskus inhalers (salmeterol or placebo). Eligible patients attended the clinic on five test days (visits 2 to 6), with each consecutive pair of visits three to five days apart.

During visits 2 to 6 , the baseline values of the $\mathrm{FEV}_{1}$ had to be within the range of $85 \%$ to $115 \%$ of the baseline $\mathrm{FEV}_{1}$ measured at visit 1 . If, on any day, the predose $\mathrm{FEV}_{1}$ value did not meet this requirement or the patient had taken rescue bronchodilator medication within the predefined washout period before baseline spirometry, the patient was instructed to return to repeat the spirometry no later than 10 days after their previously fully completed visit.

At each clinic visit, $\mathrm{FEV}_{1}$, forced vital capacity (FVC), inspiratory capacity (IC) and maximal mid-expiratory flow $\left(\mathrm{FEF}_{25-75 \%}\right)$ were measured predose, as well as at 5, 10, 15, 30 and $60 \mathrm{~min}$, and 2, 3 and $4 \mathrm{~h}$ postdose. At visits 2 to 6 , patients were asked to rate any perceived changes in dyspnea by using two visual analogue scales (vertical straight line, $100 \mathrm{~mm}$ long) - the first for the sense of effort required to breathe, and the second for the degree of discomfort associated with breathing before dosing, and at 1 and $4 \mathrm{~h}$ postdose. In addition, at visits 2 to 6 , patients rated their perception of change in breathlessness 1 and $4 \mathrm{~h}$ postdose on a -5 to +5 scale $(13,18,19)$.

\section{Interventions}

Each patient received single doses of inhaled formoterol dry powder (12 and $24 \mu \mathrm{g})$, single doses of inhaled salmeterol xinofoate $(50$ and $100 \mu \mathrm{g})$ and matching placebo in a randomized sequence. The primary comparison was between the $12 \mu \mathrm{g}$ dose of formoterol and the $50 \mu \mathrm{g}$ dose of salmeterol, because these are the most commonly prescribed doses $(7,20)$.

The study treatments were provided as formoterol dry powder capsules, each containing $12 \mu \mathrm{g}$ formoterol fumarate (Foradil); salmeterol $50 \mu \mathrm{g}$ metered dose (Serevent) delivered via the Diskus dry powder inhaler; placebo dry powder capsules; and placebo Serevent Diskus. All dry powder capsules were identical in appearance and were inhaled through the Aerolizer, a breath-actuated dry powder inhalation device. In addition, salbutamol dry powder was provided for use in reversibility testing at screening (Ventodisks $200 \mu \mathrm{g} /$ blister plus Diskhaler device). The study drugs were administered in the morning (07:00 to 10:00), and all four inhalations had to be taken at the same time and in the sequence outlined as follows: two capsules delivered by the Aerolizer followed by two inhalations from the Diskus device.

Patients were expected to avoid using bronchodilators during the $4 \mathrm{~h}$ test periods at visits 2 to 6 and during the washout periods before these visits. Treatment with inhaled or nasal corticosteroids and stable doses of oral modifiedrelease theophylline or a derivative was allowed.

\section{Efficacy evaluations}

The primary efficacy parameter was the normalized $(*)$ $\mathrm{FEV}_{1}$ area under the curve in the first hour $\left(\mathrm{FEV}_{1} \mathrm{AUC}^{*}{ }_{0-1 \mathrm{~h}}\right)$ after drug inhalation in the morning. The first hour after dosing was considered to be of paramount importance for patients with COPD under regular, twice daily beta $_{2}-$ agonist treatment because of the need of these patients for fast symptom relief. Secondary efficacy parameters included other measures of lung function, dyspnea ratings, and monitoring for safety and tolerability at various time points up to and including $4 \mathrm{~h}$ postinhalation. These were normalized $\mathrm{FEV}_{1}$ AUC over the $4 \mathrm{~h}$ period $\left(\mathrm{FEV}_{1} \mathrm{AUC}^{*}{ }_{0-4 \mathrm{~h}}\right)$, peak $\mathrm{FEV}_{1}$ and $\mathrm{FEV}_{1}$ at all time points. FVC, IC and $\mathrm{FEV}_{25-75 \%}$ were all considered in the same way. In addition, the following secondary parameters were evaluated: time to $10 \%$, $12 \%$ and $15 \%$ change in all of these parameters from baseline; number of responders with a 10\%, 12\%, 15\% and greater than $15 \%$ change in all of these parameters from baseline at 5,10 and $15 \mathrm{~min}$; and change in dyspnea ratings at $1 \mathrm{~h}$ and $4 \mathrm{~h}$. All efficacy measurements and ratings evaluated the capacity of both agonists to induce bronchodilation, reductions in the work of breathing, symptom relief, and enhancement of the individual's ability for work and exercise. A total duration of $4 \mathrm{~h}$ was chosen as this time interval and was considered to be sufficient to allow the study medication to achieve peak effect. In addition, this evaluation period was not too prolonged and was not expected to hinder patient compliance.

To reduce the variability of observations induced by known diurnal variation, measurements were taken at approximately the same time at each visit. Three determinations for the expiratory indexes were performed at each time point, and the best reading was recorded (21).

\section{Patients}

A minimum of 50 patients diagnosed with COPD of stage II and III severity according to the American Thoracic Society criteria were to be randomly assigned (8). All patients gave written informed consent. Inclusion criteria were: age 40 years or older; current or previous smoker (more than 20 pack-years); prebronchodilator baseline $\mathrm{FEV}_{1}$ of less than $50 \%$ of the predicted normal value and at least $0.7 \mathrm{~L}$ (if less than $0.7 \mathrm{~L}$ then $40 \%$ or greater of predicted normal); prebronchodilator $\mathrm{FEV}_{1} / \mathrm{FVC}$ of $70 \%$ or less; an increase in $\mathrm{FEV}_{1} 30$ min after inhalation of $400 \mu \mathrm{g}$ salbutamol dry powder at screening of $5 \%$ or greater from the baseline value and $12 \%$ or less from the patient's predicted normal value; a complaint of dyspnea of at least two months' duration before screening. European Respiratory Society standards were used to determine the predicted values for $\mathrm{FEV}_{1}$ and the $\mathrm{FEV}_{1} / \mathrm{FVC}$ ratio required to meet the study entry criteria (21).

Exclusion criteria included current or childhood asthma (21); a history of allergic rhinitis or another atopic disease; a total blood eosinophil count higher than $400 / \mu \mathrm{L}$; a respiratory tract infection within one month before screening; hospitalization or emergency room treatment for an acute 


\section{TABLE 1} Baseline demographics and spirometry for 47 patients
with stable, moderate to severe chronic obstructive
pulmonary disease included in a randomized,
double-blind study comparing single doses of
formoterol and salmeterol

\begin{tabular}{|c|c|c|}
\hline \multicolumn{3}{|l|}{ Demographic variable } \\
\hline \multirow[t]{2}{*}{ Age (years) } & Mean \pm SD & $63.5 \pm 8.6$ \\
\hline & Range & $42-80$ \\
\hline \multirow[t]{2}{*}{ Sex } & Male & $38(81 \%)$ \\
\hline & Female & $9(19 \%)$ \\
\hline Current smokers & & $28(60 \%)$ \\
\hline \multicolumn{3}{|l|}{ Spirometric test } \\
\hline \multirow[t]{2}{*}{ Pretreatment $\mathrm{FEV}_{1}(\mathrm{~L})$} & Mean \pm SD & $1.17 \pm 0.29$ \\
\hline & Range & $0.56-1.77$ \\
\hline \multirow[t]{2}{*}{ FEV 1 reversibility* (\%) } & Mean \pm SD & $17.7 \pm 7.2$ \\
\hline & Range & $6.0-34.0$ \\
\hline \multirow[t]{2}{*}{$\mathrm{FEV}_{1}$ reversibility ${ }^{*}(\%$ of predicted) } & Mean \pm SD & $7.1 \pm 2.7$ \\
\hline & Range & $3.0-13.0$ \\
\hline
\end{tabular}

*30 min after inhalation of salbutamol $400 \mu \mathrm{g}$. FEV ${ }_{1}$ Forced expiratory volume in $1 \mathrm{~s}$

COPD exacerbation in the month before screening; any clinically significant condition; long term oxygen therapy; or an inability to stop treatment with a usual bronchodilator before screening.

\section{Statistical analysis}

The primary and most of the secondary efficacy variables were analyzed using ANCOVA. Analyses were performed on both the intent-to-treat and per-protocol populations. Because of the crossover design, the intent-to-treat population was defined as all randomly assigned patients who provided postdose measurements on at least two different study days. The per-protocol population was defined as all patients completing the study without any major protocol deviations such as the incorrect selection of the patient at screening or the use of prohibited concomitant medications during the trial.

The primary efficacy variable was the $\mathrm{FEV}_{1} \mathrm{AUC}^{*}{ }_{0-1 \mathrm{~h}}$, standardized with respect to the length of time during which the patient provided serial spirometry measurements. The results of normalization, in which the AUC is divided by the measurement period, are therefore expressed either in litres (AUC in $\mathrm{L} / \mathrm{min}$ divided by 60 for $\mathrm{AUC}_{0-1 \mathrm{~h}}$ or divided by 240 for $\mathrm{AUC}_{0-4 \mathrm{~h}}$ ) or as a percentage value (AUC for the percentage increase, divided by time). Throughout the present article, normalized values are designated using an asterisk as AUC*. The ANCOVA used a fixed effects model, fitting treatment, centre and period as main effects, with the treatment baseline (visit predose value) fitted as a covariate. All 10 pairwise contrasts were estimated, but the comparison of formoterol $12 \mu \mathrm{g}$ and salmeterol $50 \mu \mathrm{g}$ was considered to be of prime interest. Analysis of secondary variables was carried out in a similar way.

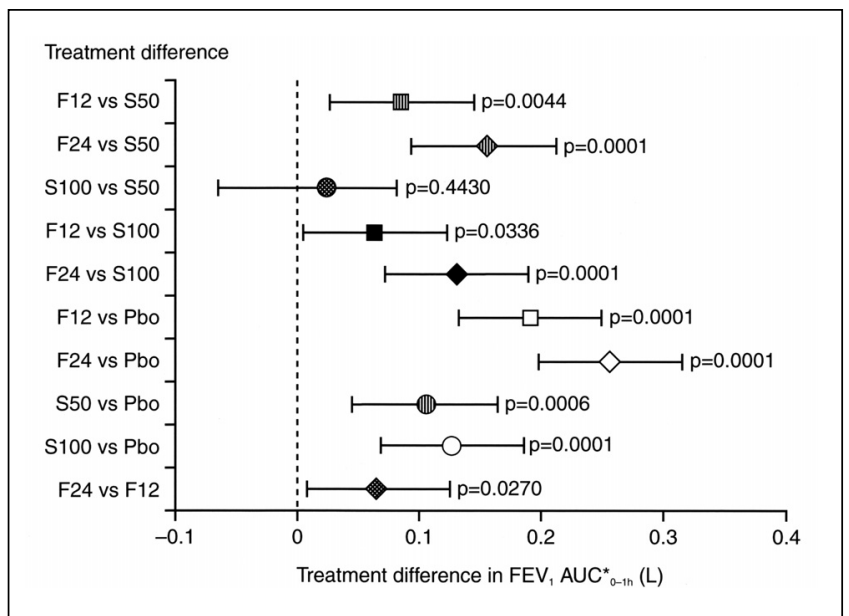

Figure 1) Treatment differences in normalized forced expiratory volume in $1 \mathrm{~s}$ area under the curve $\left(\mathrm{FEV}_{1} \mathrm{AUC}^{*}{ }_{0-1} \mathrm{~h}\right)$ for the intentto-treat population. Results are shown as estimated treatment differences and 95\% CIs using ANCOVA based on the model $\mathrm{AUC}^{*}=\mu+$ treatment + predose $\mathrm{FEV}_{1}+$ centre + period. F12 Formoterol $12 \mu \mathrm{g}$; F24 Formoterol $24 \mu \mathrm{g}$; Pbo Placebo; S50 Salmeterol $50 \mu \mathrm{g} ;$ S100 Salmeterol $100 \mu \mathrm{g}$; vs Versus

For the estimation of the sample size, a difference of $5 \%$ (assuming an SD of 10\%) between formoterol $12 \mu \mathrm{g}$ and salmeterol $50 \mu \mathrm{g}$ in terms of the primary variable, $\mathrm{FEV}_{1} \mathrm{AUC}^{*}{ }_{0-1 \mathrm{~h}}$, was considered to be clinically important. To demonstrate superiority with $85 \%$ power (significance level $5 \%$, two-sided), a minimum of 38 evaluable patients were needed. Consequently, it was decided to recruit a minimum of 50 patients to allow for patients who discontinued the trial prematurely.

\section{Patients}

\section{RESULTS}

Five centres in four countries participated in the study - one centre each in France, Greece and Italy, and two centres in the Netherlands. Sixty-eight patients were screened, and 47 were randomly assigned and treated. A summary of patient demographics is presented in Table 1. All patients who were included achieved the minimum value of $5 \%$ reversibility, and only one patient failed to meet the inclusion criterion maximum limit for reversibility (12\%), with an increase of $13 \%$ of predicted normal. This patient was not excluded from the per-protocol evaluation, because the deviation was considered to be slight.

\section{Efficacy}

The superiority of formoterol $12 \mu \mathrm{g}$ over salmeterol $50 \mu \mathrm{g}$ with respect to the primary efficacy variable, $\mathrm{FEV}_{1} \mathrm{AUC}^{*}{ }_{0-1 \mathrm{~h}}$, was demonstrated by a statistically significant difference for both absolute values of $\mathrm{FEV}_{1}$ and for the percentage change from predose value, with estimated treatment differences of $0.086 \mathrm{~L}(\mathrm{P}=0.0044)$ and $7.8 \%(\mathrm{P}=0.0021)$, respectively, for the intent-to-treat population (Figure 1). This was confirmed by the results for the per-protocol population, which 


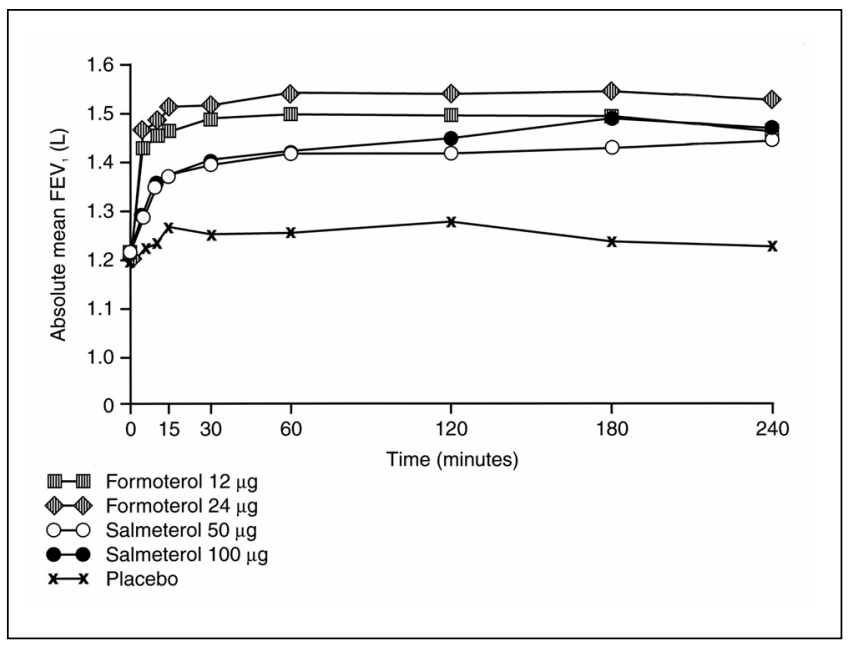

Figure 2) Mean forced expiratory volume in $1 \mathrm{~s}\left(\mathrm{FEV}_{1}\right)$ over time after administration of formoterol $12 \mu \mathrm{g}$ or $24 \mu \mathrm{g}$, salmeterol $50 \mu \mathrm{g}$ or $100 \mu \mathrm{g}$, or placebo as single dose dry powder inhalations in the intentto-treat population

gave very similar estimates of $0.087 \mathrm{~L}(\mathrm{P}=0.0100)$ and $7.1 \%$ $(\mathrm{P}=0.0088)$. The higher dose of formoterol $(24 \mu \mathrm{g})$ was also shown to be statistically superior to the higher dose of salmeterol $(100 \mu \mathrm{g})$, with estimated treatment differences of $0.130 \mathrm{~L}(\mathrm{P}=0.0001)$ and $12.4 \%(\mathrm{P}=0.0001)$. Both doses of formoterol were statistically significant compared with placebo, confirming the sensitivity of the trial. These results for the primary variable support the claim that the effect of formoterol is superior to that of salmeterol during the first hour after dosing.

Analysis of the $\mathrm{FEV}_{1}$ at individual time points up to $4 \mathrm{~h}$ also highlighted the rapid onset of action of formoterol compared with salmeterol, with statistically significant differences between formoterol $12 \mu \mathrm{g}$ and salmeterol $50 \mu \mathrm{g}$ at
$5,10,15,30$ and 60 min postdose (Figure 2). At these time points, estimated mean treatment differences were $0.130 \mathrm{~L}$ $(\mathrm{P}=0.0001), 0.115 \mathrm{~L}(\mathrm{P}=0.0003), 0.089 \mathrm{~L} \quad(\mathrm{P}=0.0123)$, $0.092 \mathrm{~L}(\mathrm{P}=0.0105)$ and $0.073 \mathrm{~L}(\mathrm{P}=0.0349)$, respectively.

The estimated treatment difference for the main contrast of formoterol $12 \mu \mathrm{g}$ versus salmeterol $50 \mu \mathrm{g}$ in $\mathrm{FEV}_{1}$ AUC $^{*}{ }_{0-4} \mathrm{~h}$ was $0.067 \mathrm{~L}$ (mean absolute difference), but did not achieve statistical significance $(\mathrm{P}=0.0577)$. However, the estimated difference in terms of percentage change $6.1 \%$ - was statistically significant $(\mathrm{P}=0.0350)$.

For peak $\mathrm{FEV}_{1}$ in the intent-to-treat population, the main contrast (formoterol $12 \mu \mathrm{g}$ versus salmeterol $50 \mu \mathrm{g}$ ) did not achieve statistical significance (estimated mean difference formoterol - salmeterol 0.076 L, P=0.0948). The comparison of formoterol $24 \mu \mathrm{g}$ with salmeterol $50 \mu \mathrm{g}$ (estimated mean difference $0.164 \mathrm{~L}$ ) was statistically significant $(\mathrm{P}=0.0004)$. Patients treated with formoterol $24 \mu \mathrm{g}$ reached the highest mean peak $\mathrm{FEV}_{1}$ value $(1.63 \mathrm{~L})$ followed by patients treated with formoterol $12 \mu \mathrm{g}(1.58 \mathrm{~L})$. The mean peak $\mathrm{FEV}_{1}$ values for salmeterol were $1.54 \mathrm{~L}$ for the $100 \mu \mathrm{g}$ dose and $1.49 \mathrm{~L}$ for the $50 \mu \mathrm{g}$ dose. Patients showed a mean peak $\mathrm{FEV}_{1}$ of $1.36 \mathrm{~L}$ with placebo.

Formoterol also had a faster onset of action than salmeterol when evaluated in temporal terms (Table 2). The median times to $10 \%, 12 \%, 15 \%$ and maximum percentage change in $\mathrm{FEV}_{1}$ from predose levels were shorter for formoterol 12 and $24 \mu \mathrm{g}$ compared with salmeterol 50 and $100 \mu \mathrm{g}$ and placebo. In addition, more formoterol recipients achieved a $10 \%, 12 \%$ or $15 \%$ change (Table 2 ), and almost twice as many formoterol than salmeterol recipients reached a $10 \%, 12 \%$ or $15 \%$ change from predose levels at 5 min (Table 3).

While $\mathrm{FEV}_{1}$ is the most commonly used measure for assessing bronchodilation, other spirometric indices are also important. The mean treatment differences in FVC

\section{TABLE 2}

Time $^{*}(\mathrm{~min})$ to $10 \%, 12 \%, 15 \%$ and maximum change from baseline forced expiratory volume in $1 \mathrm{~s}$ for the intent-to-treat population in a randomized, double-blind study comparing single doses of formoterol and salmeterol in patients with chronic obstructive pulmonary disease

\begin{tabular}{|c|c|c|c|c|c|c|}
\hline & & Formoterol $12 \mu \mathrm{g}$ & Formoterol $24 \mu \mathrm{g}$ & Salmeterol $50 \mu \mathrm{g}$ & Salmeterol $100 \mu \mathrm{g}$ & Placebo \\
\hline \multirow[t]{3}{*}{$10 \%$} & $\mathrm{n}(\%)$ & $41(83)$ & $44(98)$ & $39(87)$ & $39(85)$ & $29(64)$ \\
\hline & Median & 5 & 5 & 10 & 10 & 15 \\
\hline & Range & $5-180$ & $5-120$ & $5-240$ & $5-240$ & $5-120$ \\
\hline \multirow[t]{3}{*}{$12 \%$} & $\mathrm{n}(\%)$ & $41(93)$ & $44(98)$ & $36(80)$ & $36(78)$ & $23(51)$ \\
\hline & Median & 5 & 5 & 10 & 10 & 15 \\
\hline & Range & $5-180$ & $5-180$ & $5-240$ & $5-120$ & $5-180$ \\
\hline \multirow[t]{3}{*}{$15 \%$} & $\mathrm{n}(\%)$ & $39(89)$ & $43(96)$ & $32(71)$ & $34(74)$ & $18(40)$ \\
\hline & Median & 5 & 5 & 15 & 10 & 22.5 \\
\hline & Range & $5-180$ & $5-180$ & $5-240$ & $5-240$ & $5-120$ \\
\hline \multirow[t]{3}{*}{ Maximum } & $\mathrm{n}(\%)$ & $44(100)$ & $45(100)$ & $45(100)$ & $46(100)$ & $45(100)$ \\
\hline & Median & 60 & 60 & 120 & 150 & 30 \\
\hline & Range & $5-240$ & $5-240$ & $10-240$ & $5-240$ & $5-240$ \\
\hline
\end{tabular}

*The first postdose assessment was performed at $5 \mathrm{~min}$; therefore, the medians are probably overestimating time to onset 
TABLE 3

Number of responders classified by percentage change from baseline forced expiratory volume in $1 \mathrm{~s}$ at $5 \mathrm{~min}$ for the intent-to-treat population in a randomized, double-blind study comparing single doses of formoterol and salmeterol in patients with chronic obstructive pulmonary disease

\begin{tabular}{|c|c|c|c|c|c|}
\hline & $\begin{array}{l}\text { Formoterol } 12 \mu g \\
(n=44)(\%)\end{array}$ & $\begin{array}{l}\text { Formoterol } 24 \mu \mathrm{g} \\
(\mathrm{n}=45)(\%)\end{array}$ & $\begin{array}{l}\text { Salmeterol } 50 \mu \mathrm{g} \\
\quad(n=45)(\%)\end{array}$ & $\begin{array}{c}\text { Salmeterol } 100 \mu g \\
(n=46)(\%)\end{array}$ & $\begin{array}{c}\text { Placebo } \\
(n=45)(\%)\end{array}$ \\
\hline $10 \%$ & $31(76)$ & 39 (89) & $12(31)$ & $19(49)$ & $5(17)$ \\
\hline $12 \%$ & $26(63)$ & $37(84)$ & $10(28)$ & $13(36)$ & $4(17)$ \\
\hline $15 \%$ & $23(59)$ & $32(74)$ & $7(22)$ & $9(27)$ & $3(17)$ \\
\hline
\end{tabular}

\section{TABLE 4}

ANCOVA of the absolute changes in effort to breathe and degree of breathing discomfort from predose for the intent-to-treat population in a randomized, double-blind study comparing single doses of formoterol and salmeterol in patients with chronic obstructive pulmonary disease

\begin{tabular}{|c|c|c|c|c|}
\hline Contrast (difference) & Time point (h) & Estimated difference $(\mathrm{mm})^{*}$ & $95 \% \mathrm{Cl}$ & $\mathbf{P}$ \\
\hline \multicolumn{5}{|l|}{ Effort to breathe } \\
\hline \multirow[t]{2}{*}{ Formoterol $12 \mu \mathrm{g}$ - salmeterol $50 \mu \mathrm{g}$} & 1 & -4.546 & $(-9.731$ to 0.638$)$ & 0.0853 \\
\hline & 4 & -3.827 & $(-9.674$ to 2.020$)$ & 0.1984 \\
\hline \multicolumn{5}{|l|}{ Degree of breathing discomfort } \\
\hline \multirow[t]{2}{*}{ Formoterol $12 \mu \mathrm{g}$ - salmeterol $50 \mu \mathrm{g}$} & 1 & -5.201 & $(-10.720$ to 0.318$)$ & 0.0646 \\
\hline & 4 & -4.404 & $(-10.440$ to 1.632$)$ & 0.1519 \\
\hline
\end{tabular}

${ }^{*}$ Based on the model: Visual analogue scale (VAS) (time) - VAS predose $=\mu+$ treatment + VAS (at predose $)+$ centre + period

$\mathrm{AUC}^{*}{ }_{0-1 \mathrm{~h}}$ results for the intent-to-treat population showed that formoterol was statistically significantly superior to salmeterol and placebo for all pair contrasts; the two formoterol doses did not differ significantly. For the main contrast (formoterol $12 \mu \mathrm{g}$ versus salmeterol $50 \mu \mathrm{g}$ ), the mean AUC $^{*}{ }_{0-1}$ h difference for FVC was $0.137 \mathrm{~L}$ $(\mathrm{P}=0.0135)$ in absolute terms. The difference between these two treatments was most marked at 5 min (estimated treatment difference $0.293 \mathrm{~L}, \mathrm{P}=0.0001$ ) and $10 \mathrm{~min}$ (0.247 L, P=0.0012). Both doses of formoterol show statistically significant differences versus placebo at each time point after dosing.

For IC AUC* ${ }_{0-1 \mathrm{~h}}$, the estimated difference between formoterol $12 \mu \mathrm{g}$ and salmeterol $50 \mu \mathrm{g}$ (the main treatment contrast) was $0.142 \mathrm{~L}(\mathrm{P}=0.0096)$. In addition, for IC AUC $^{*}{ }_{0-1} \mathrm{~h}$, the estimated differences were not statistically significant for the contrast between the two formoterol doses and the two salmeterol doses, and for the contrast between formoterol $12 \mu \mathrm{g}$ and salmeterol $100 \mu \mathrm{g}$.

All treatment pairs for the mean $\mathrm{FEF}_{25-75 \%}$ AUC* ${ }_{0-1 \mathrm{~h}}$ contrasts for the intent-to-treat population showed statistical superiority for formoterol compared with salmeterol or placebo. For the main contrast (formoterol $12 \mu \mathrm{g}$ versus salmeterol $50 \mu \mathrm{g}$ ), the estimated mean AUC* difference was $0.058 \mathrm{~L} / \mathrm{min}$ using actual values or $11.3 \%$ using percentage change from predose in favour of formoterol $(\mathrm{P}=0.078$ and $\mathrm{P}=0.0187$, respectively).

Subjective assessments by patients of relief from dyspnea were also investigated. The results for the main contrast (formoterol $12 \mu \mathrm{g}$ versus salmeterol $50 \mu \mathrm{g}$ ) for absolute changes in effort to breathe and degree of breathing discomfort from predose for the intent-to-treat population are shown in Table 4. For effort to breathe, there were no statistically significant differences between treatments, and similarly, the primary contrast for degree of breathing discomfort was not statistically significant. For change in effort to breathe, the reduction in effort was also similar for the formoterol and salmeterol treatment groups at 1 and $4 \mathrm{~h}$ postdose (Table 5).

\section{Safety}

Five patients $(10.6 \%)$ reported eight adverse events, none of which was considered to be related to the study drug. Five adverse events were classed as moderate in intensity, two as mild and one as severe. Two patients had adverse events that led to discontinuation. Both patients experienced a COPD exacerbation of moderate severity that was judged to be unrelated to the study drug; one patient received formoterol $24 \mu \mathrm{g}$ and the other salmeterol $100 \mu \mathrm{g}$. There were no differences in blood pressure and pulse rate measurements.

\section{DISCUSSION}

The results of the present study indicate that formoterol has a significantly faster onset of effect than salmeterol in patients with COPD. For those doses most frequently used in patients with COPD (formoterol $12 \mu \mathrm{g}$ and salmeterol $50 \mu \mathrm{g}$ ), primary efficacy results with respect to the $\mathrm{FEV}_{1}$ AUC ${ }_{0-1 \mathrm{~h}}$ showed a statistically significant difference of 0.086 L. In addition, the $\mathrm{FEV}_{1}$ was statistically significantly 
TABLE 5

The effects of formoterol and salmeterol on the sense of effort required to breathe (the results are shown as the changes in score from predose values, assessed on a visual analogue scale [mm])

\begin{tabular}{|c|c|c|c|c|c|}
\hline & $\begin{array}{l}\text { Formoterol } \\
12 \mu g(n=44)\end{array}$ & $\begin{array}{c}\text { Formoterol } \\
24 \mu g(n=45)\end{array}$ & $\begin{array}{c}\text { Salmeterol } \\
50 \mu g(n=45)\end{array}$ & $\begin{array}{c}\text { Salmeterol } \\
100 \mu g(n=46)\end{array}$ & $\begin{array}{c}\text { Placebo } \\
(n=45)\end{array}$ \\
\hline \multicolumn{6}{|c|}{$1 \mathrm{~h}$ postdose } \\
\hline n (\%) & $40(90.9)$ & $41(91.1)$ & 41 (91.1) & $42(91.3)$ & 42 (93.3) \\
\hline Mean & -1.4 & -1.4 & -1.1 & -1.0 & -0.7 \\
\hline SD & 1.3 & 1.4 & 1.3 & 1.3 & 1.2 \\
\hline Median & -1.0 & -1.0 & -1.0 & -1.0 & -1.0 \\
\hline Range & -4.0 to 1.0 & -5.0 to 1.0 & -5.0 to 0.0 & -4.0 to 2.0 & -3.0 to 3.0 \\
\hline \multicolumn{6}{|c|}{$4 \mathrm{~h}$ postdose } \\
\hline n (\%) & $40(90.9)$ & $41(91.1)$ & $41(91.1)$ & $43(93.5)$ & 41 (91.1) \\
\hline Mean & -0.8 & -0.8 & -0.6 & -0.8 & -0.2 \\
\hline SD & 1.2 & 1.4 & 1.0 & 1.4 & 1.1 \\
\hline Median & 0.0 & 0.0 & 0.0 & -1.0 & 0.0 \\
\hline Range & -5.0 to 1.0 & -5.0 to 1.0 & -4.0 to 1.0 & -4.0 to 3.0 & -3.0 to 3.0 \\
\hline
\end{tabular}

higher with formoterol than with salmeterol at all time points from $5 \mathrm{~min}$ up to and including $60 \mathrm{~min}$ postdose. The reliability of these study results was confirmed by the statistically significantly better results of both formoterol doses over placebo. Also, the time to 10\%, 12\%, 15\% and maximum change in $\mathrm{FEV}_{1}$ from its baseline value, and the number of patients responding with such changes, though not statistically tested between treatments, indicate a faster onset of effect with formoterol $12 \mu \mathrm{g}$ during the first hour postdose. The median time to $15 \%$ increase in $\mathrm{FEV}_{1}$ from predose (a bronchodilatory response that is generally accepted as significant) for both formoterol doses was $5 \mathrm{~min}$, whereas for salmeterol $50 \mu \mathrm{g}$, it was $15 \mathrm{~min}$, and for salmeterol $100 \mu \mathrm{g}$, it was $10 \mathrm{~min}$. It should, however, be noted that the first postdose $\mathrm{FEV}_{1}$ assessment was performed at $5 \mathrm{~min}$, suggesting the possibility that an earlier assessment would result in more marked differences between the two drugs tested.

A bronchodilator with a rapid onset of effect may be particularly important in patients with COPD, in which patients experience progressive and long term debilitating symptoms. This is because such a bronchodilator would result in a fast enhancement of exertion tolerance (22), with a corresponding reduction in the work of breathing and rapid relief of symptoms (23), and such rapid effects, readily discernible by the patient, would provide reassurance. Thus, these effects may improve compliance. In the context of the results of the present investigation, however, the obvious question is: what is the clinical relevance of the observed difference of $0.086 \mathrm{~L}$ with formoterol $12 \mu \mathrm{g}$ during the first hour postdose? In this trial, three scales were used to evaluate dyspnea ratings to relate any improvement in lung function with clinically meaningful outcomes. The results from these subjective assessments showed small advantages with active treatments over placebo, but no statistically signifi- cant difference between the primary treatment contrasts for the sense of effort required to breathe or the degree of discomfort associated with breathing. In addition, change in perception of breathlessness from predose to 1 and $4 \mathrm{~h}$ postdose showed no statistical difference between the treatment groups. Although these results suggest that the observed improvement in lung function was not associated with any meaningful clinical improvements, the assessments of dyspnea were performed at 1 and $4 \mathrm{~h}$ postdose, and not during the first hour postdose, when the faster onset of effect associated with formoterol was more pronounced. Thus, earlier assessment of dyspnea may have revealed a meaningful outcome. More importantly, patients with COPD tend to adopt relatively sedentary lifestyles with low levels of activity to avoid symptoms; thus, the clinical significance of $0.086 \mathrm{~L}$ in $\mathrm{FEV}_{1}$ AUC* $^{*}$ during the first hour after dosing can only really be judged in an experimental exercise setting.

It has become apparent that changes in $\mathrm{FEV}_{1}$ are unlikely to produce a reliable guide to symptomatic improvement in COPD, and some investigators believe that measurement of IC may correlate better with improvements in exercise endurance and dyspnea after bronchodilator therapy, because they provide an indirect measure of dynamic changes in lung hyperinflation (24,25). Because serial measurements of IC during exercise may be problematic for many physicians who manage patients with COPD, O'Donnell et al (24) have recently investigated the value of resting IC measurement in evaluating clinical response, and have shown that these correlate well with improvements in exercise endurance and dyspnea after anticholinergic therapy in patients with severe COPD. In the present study, IC AUC* ${ }_{0-1 \mathrm{~h}}$ results showed a statistically significant difference between the main treatment contrast of $0.142 \mathrm{~L}$, which may be suggestive of a greater clinical response from formoterol compared with salmeterol. 
The results of the present study suggest that further, more in-depth investigations would be valuable. In patients with advanced disease, even modest improvements in symptoms can lead to quite important perceived benefits and can have a real impact on quality of life. In particular, further studies are needed to assess any potential differences between formoterol and salmeterol in terms of improvements in breathlessness during exercise, and to relate these to assessments of quality of life. The rapid onset of action of formoterol shown in this study confirms previous results by Dahl et al $(9,10)$, who showed an onset of action of less than 5 min in a study comparing formoterol with ipratropium bromide in patients with COPD. Results from comparative studies in patients with COPD have also shown that the onset of action in terms of $\mathrm{FEV}_{1}$ increase is greater for formoterol than salmeterol (26) and similar to that of salbutamol (27). Our results do not, however, reproduce the results of Cazzola et al (28), who showed formoterol to be slower in onset than salbutamol and similar to salmeterol in patients with COPD. The difference in results seen in the Cazzola study (28) may be attributable to differences in methodology, patient population studied and inhalers used. With respect to the latter, all medications were administered via metered dose inhalers in the Cazzola study (28), whereas in the present study, formoterol and salmeterol were administered via dry powder inhalers (Aerolizer for formoterol, Diskus for salmeterol). A

\section{REFERENCES}

1. Derom E, Pauwels RA. Time-course of bronchodilating effect of inhaled formoterol, a potent and long acting sympathomimetic. Thorax 1992;47:30-3.

2. Wallin A, Sandström T, Rosenhall L, et al. Time course and duration of bronchodilatation with formoterol dry powder in patients with stable asthma. Thorax 1993;48:611-4.

3. van Noord JA, Smeets JJ, Raaijmakers JA, et al. Salmeterol versus formoterol in patients with moderately severe asthma: onset and duration of action. Eur Respir J 1996;9:1684-8.

4. Maesen FPV, Smeets JJ, Gubbelmans HLL, et al. Bronchodilator effect of inhaled formoterol vs salbutamol over 12 hours. Chest 1990;97:590-4.

5. Wegener T, Hedenström H, Melander B. Rapid onset of action of inhaled formoterol in asthmatic patients. Chest 1992;102:535-8.

6. Lötvall J, Lunde H, Svedmyr N. Onset of bronchodilation and finger tremor induced by salmeterol and salbutamol in asthmatic patients. Can Respir J 1998;5:91-4.

7. Brogden RN, Faulds D. Salmeterol xinofoate: a review of its pharmacological properties and therapeutic potential in reversible obstructive airways disease. Drugs 1991;42:895-912.

8. American Thoracic Society. Standards for the diagnosis and care of patients with chronic obstructive pulmonary disease. Am J Respir Crit Care Med 1995;152(Suppl):77S-120S.

9. Dahl R, Greefhorst LAPM, Nowak D, et al. Inhaled formoterol dry powder versus ipratropium bromide in chronic obstructive pulmonary disease. Am J Respir Crit Care Med 2001;164:778-84.

10. Dahl R, Greefhorst APM, Nowak D, et al. Onset of action of inhaled formoterol compared to ipratropium bromide in patients with COPD. Eur Respir J 2000;16(Suppl 31):51S.

11. Rossi A, Kristufek P, Levine BE, et al. Comparison of the efficacy, tolerability and safety of formoterol dry powder and oral slow-release theophylline in the treatment of COPD. Chest. (In press)

12. Mahler DA, Donohue JF, Barbee RA, et al. Efficacy of salmeterol xinofoate in the treatment of COPD. Chest 1999;115:957-65.

13. Ramirez-Venegas A, Ward J, Lentine T, et al. Salmeterol reduces dyspnea and improves lung function in patients with COPD. Chest 1997;112:336-40. recent study by Benhamou et al (29) also refuted the findings of Cazzola et al (28); it showed that formoterol $24 \mu \mathrm{g}$ and salbutamol $400 \mu \mathrm{g}$ had a similar onset of action in patients with COPD; both drugs produced similar bronchodilation by $5 \mathrm{~min}$, which became near maximal at $30 \mathrm{~min}$ (29). Overall, these findings do not support the argument posed by Cazzola and Donner (30) that the discrepancy is due to greater activity of salmeterol than formoterol in patients with severe COPD.

\section{CONCLUSIONS}

In patients with COPD, formoterol is associated with a faster onset of effect during the first hour postdose compared with salmeterol. The clinical relevance of this finding warrants further investigation by means of properly designed, longer term clinical trials looking at the impact of treatment with formoterol on quality of life and exertion endurance.

ACKNOWLEDGEMENTS: This study was supported by a research grant from Novartis Pharma AG, Basel, Switzerland. The authors and all study investigators have not entered into any financial arrangement whereby the value of the compensation could be influenced by the outcome of the investigation; they have not received significant payments in kind from the sponsor, excluding the cost of the study. John Kottakis, Giovanni Della Cioppa, Tim Overend, Denise Till, Günter Rapatz and Vincent Le Gros are employees of Novartis Pharmaceuticals.

14. Appleton S, Smith B, Veale A, et al. Long-acting beta 2 -agonists for chronic obstructive pulmonary disease (Cochrane Review). In: The Cochrane Library, Issue 1. Oxford: Update Software, 2001.

15. Anderson GP. Formoterol: pharmacology, molecular basis of agonism, and mechanism of long duration of a potent and selective beta-2-andrenoceptor agonist bronchodilator. Life Sci 1993;52:2145-60.

16. Siafakas NM, Vermeire P, Pride NB, et al. ERS consensus statement: optimal assessment and management of chronic obstructive pulmonary disease (COPD). Eur Respir J 1995;8:1398-420.

17. British Thoracic Society. BTS guidelines for the management of chronic obstructive pulmonary disease. Thorax 1997;52(Suppl 5):1S-28S.

18. Jeffema Mador M, Kufel TJ. Reproducibility of visual analog scale measurements of dyspnea in patients with chronic obstructive pulmonary disease. Am Rev Respir Dis 1992;146:82-7.

19. O'Donnell DE, Sanii R, Giesbrecht G, et al. Effect of continuous positive airway pressure on respiratory sensation in patients with chronic obstructive pulmonary disease during submaximal exercise. Am Rev Respir Dis 1988;138:1185-91.

20. Bartow RA, Brogden RN. Formoterol: an update of its pharmacological properties and therapeutic efficacy in the management of asthma. Drugs 1998;55:303-22.

21. Quanjer PH, Tammeling GJ, Cotes JE, et al. Lung volumes and forced ventilatory flows. Official statement of the European Respiratory Society. Eur Respir J 1993;6(Suppl 16):5S-40S.

22. Fuso L, Spadaro S, Tramaglino LM, et al. Formoterol improves the exercise performance in patients with chronic obstructive pulmonary disease. Am J Respir Crit Care Med 1999;14(Suppl 30):282S.

23. Maesen BLP, Westermann CJJ, Duurkens VAM, van den Bosch JMM. Effects of formoterol in apparently poorly reversible chronic obstructive pulmonary disease. Eur Respir J 1999;13:1103-8.

24. O'Donnell DE, Lam M, Webb KA. Spirometric correlates of improvement in exercise performance after anticholinergic therapy in chronic obstructive lung disease. Am J Respir Crit Care Med 1999; 160:542-9.

25. Belman MJ, Botnick WC, Shin JW. Inhaled bronchodilators reduce dynamic hyperinflation during exercise in patients with chronic 
obstructive pulmonary disease. Am J Respir Crit Care Med 1996;153:967-75.

26. Celik G, Kayacan O, Beder S, et al. Formoterol and salmeterol in partially reversible chronic obstructive pulmonary disease: a crossover, placebo-controlled comparison of onset and duration of action. Respiration 1999;66:434-9.

27. Cazzola M, Centanni S, Regorda C, et al. Onset of action of single doses of formoterol administered via Turbuhaler in patients with stable COPD. Pulm Pharmacol Ther 2001;14:41-5.
28. Cazzola M, Santangelo G, Piccolo A, et al. Effect of salmeterol and formoterol in patients with chronic obstructive pulmonary disease. Pulm Pharmacol 1994;7:103-7.

29. Benhamou D, Cuvelier A, Muir JF, et al. Rapid onset of bronchodilation in COPD: a placebo-controlled study comparing formoterol (Foradil Aerolizer) with salbutamol (Ventodisk). Respir Med 2001;95:817-21.

30. Cazzola M, Donner CF. Long acting $\beta_{2}$-agonists in the management of stable chronic obstructive pulmonary disease. Drugs 2000;60:307-20. 


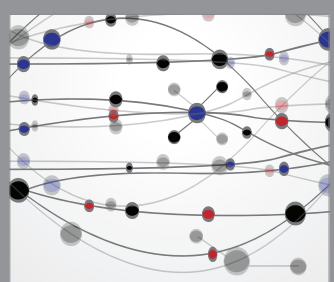

The Scientific World Journal
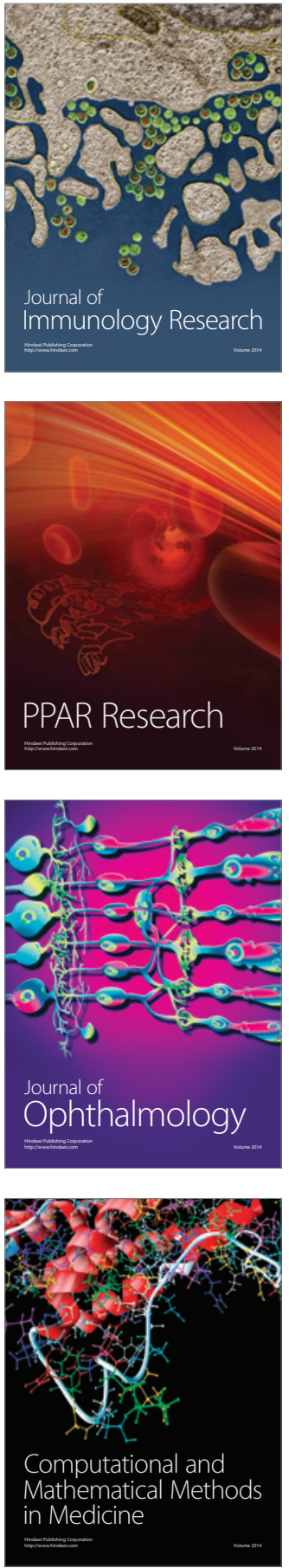

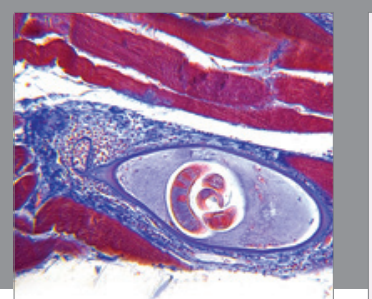

Gastroenterology Research and Practice

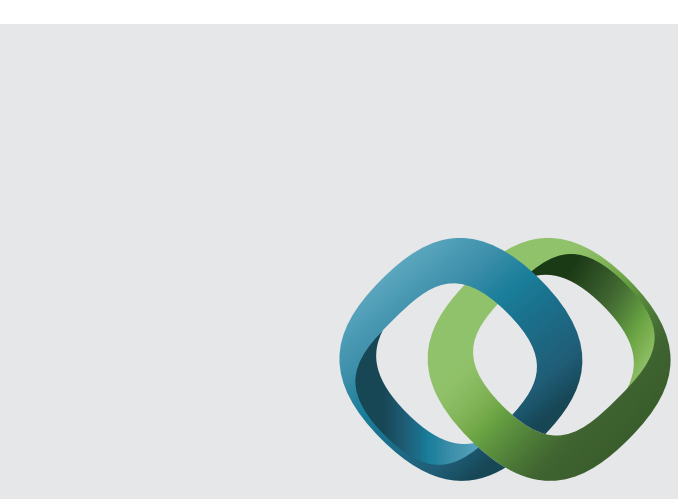

\section{Hindawi}

Submit your manuscripts at

http://www.hindawi.com
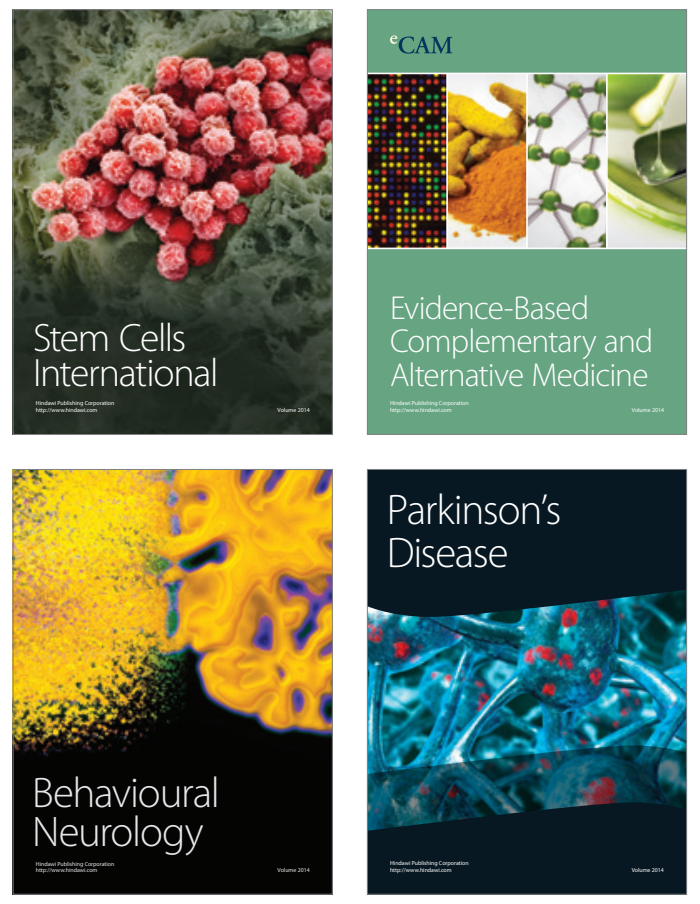
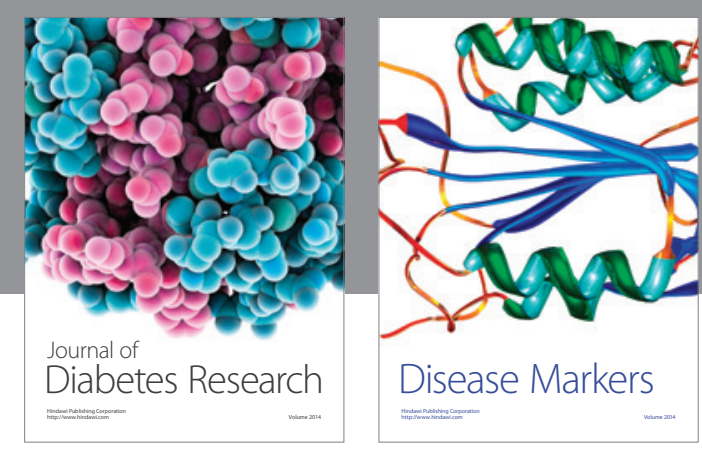

Disease Markers
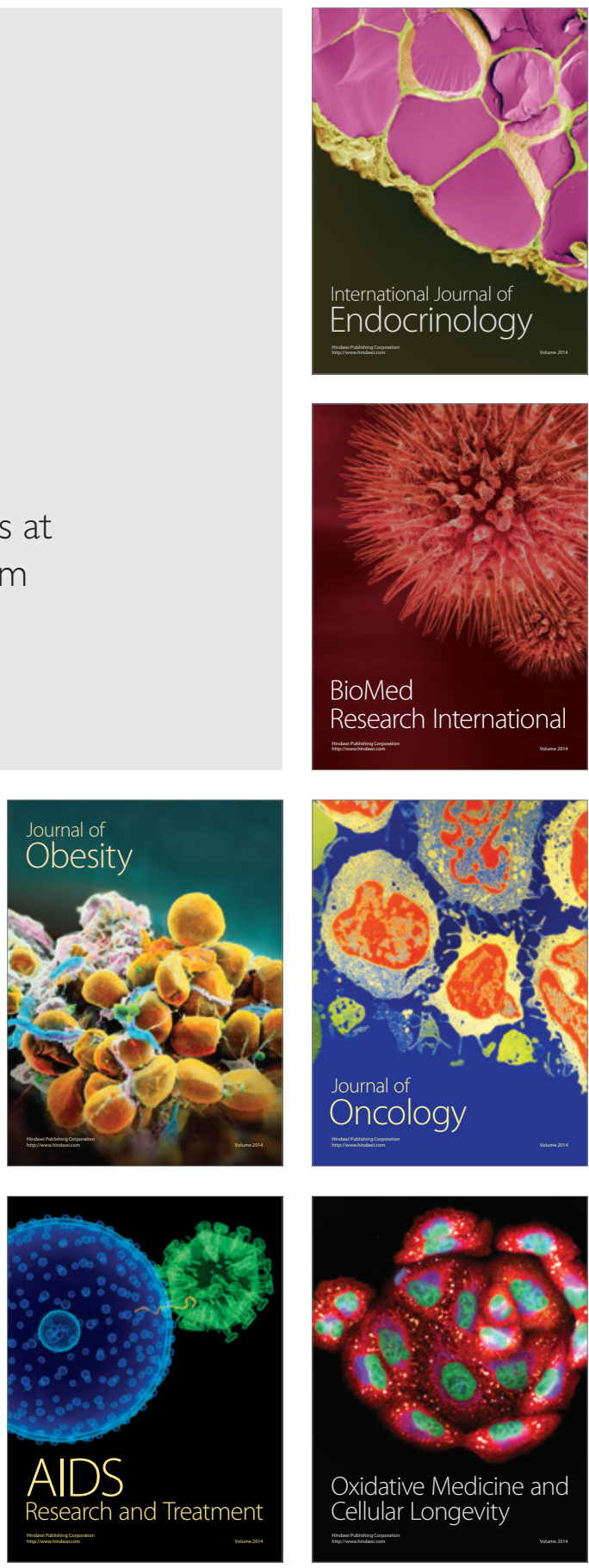